\title{
Calcium signaling recruits substrate transporters GLUT4 and CD36 to the sarcolemma without increasing cardiac substrate uptake
}

Citation for published version (APA):

Angin, Y., Schwenk, R. W., Nergiz-Unal, R., Hoebers, N., Heemskerk, J. W. M., Kuijpers, M. J., Coumans, W. A., van Zandvoort, M. A. M. J., Bonen, A., Neumann, D., Glatz, J. F. C., \& Luiken, J. (2014). Calcium signaling recruits substrate transporters GLUT4 and CD36 to the sarcolemma without increasing cardiac substrate uptake. American Journal of Physiology : Endocrinology and Metabolism, 307(2), E225-E236. https://doi.org/10.1152/ajpendo.00655.2013

Document status and date:

Published: 15/07/2014

DOI:

10.1152/ajpendo.00655.2013

Document Version:

Publisher's PDF, also known as Version of record

\section{Document license:}

Taverne

Please check the document version of this publication:

- A submitted manuscript is the version of the article upon submission and before peer-review. There can be important differences between the submitted version and the official published version of record.

People interested in the research are advised to contact the author for the final version of the publication, or visit the DOI to the publisher's website.

- The final author version and the galley proof are versions of the publication after peer review.

- The final published version features the final layout of the paper including the volume, issue and page numbers.

Link to publication

\footnotetext{
General rights rights.

- You may freely distribute the URL identifying the publication in the public portal. please follow below link for the End User Agreement:

www.umlib.nl/taverne-license

Take down policy

If you believe that this document breaches copyright please contact us at:

repository@maastrichtuniversity.nl

providing details and we will investigate your claim.
}

Copyright and moral rights for the publications made accessible in the public portal are retained by the authors and/or other copyright owners and it is a condition of accessing publications that users recognise and abide by the legal requirements associated with these

- Users may download and print one copy of any publication from the public portal for the purpose of private study or research.

- You may not further distribute the material or use it for any profit-making activity or commercial gain

If the publication is distributed under the terms of Article $25 \mathrm{fa}$ of the Dutch Copyright Act, indicated by the "Taverne" license above, 


\title{
Calcium signaling recruits substrate transporters GLUT4 and CD36 to the sarcolemma without increasing cardiac substrate uptake
}

\author{
Yeliz Angin, ${ }^{1}$ Robert W. Schwenk, ${ }^{1}$ Reyhan Nergiz-Unal, ${ }^{2}$ Nicole Hoebers, ${ }^{1}$ Johan W. M. Heemskerk, ${ }^{2}$ \\ Marijke J. Kuijpers, ${ }^{2}$ Will A. Coumans, ${ }^{1}$ Marc A. M. J. van Zandvoort, ${ }^{3}$ Arend Bonen, ${ }^{4}$ \\ Dietbert Neumann, ${ }^{1}$ Jan F. C. Glatz, ${ }^{1}$ and Joost J. F. P. Luiken ${ }^{1}$ \\ Departments of ${ }^{1}$ Molecular Genetics, ${ }^{2}$ Biochemistry and ${ }^{3}$ Molecular Cell Biology, School for Cardiovascular Diseases, \\ Maastricht University, Maastricht, The Netherlands; ${ }^{4}$ Department of Human Health and Nutritional Sciences, University of \\ Guelph, Guelph, Ontario, Canada
}

Submitted 27 November 2013; accepted in final form 1 June 2014

\begin{abstract}
Angin Y, Schwenk RW, Nergiz-Unal R, Hoebers N, Heemskerk JW, Kuijpers MJ, Coumans WA, van Zandvoort MA, Bonen A, Neumann D, Glatz JF, Luiken JJ. Calcium signaling recruits substrate transporters GLUT4 and CD36 to the sarcolemma without increasing cardiac substrate uptake. Am J Physiol Endocrinol Metab 307: E225-E236, 2014. First published June 3, 2014; doi:10.1152/ajpendo.00655.2013.-Activation of AMP-activated protein kinase (AMPK) in cardiomyocytes induces translocation of glucose transporter GLUT4 and long-chain fatty acid (LCFA) transporter CD36 from endosomal stores to the sarcolemma to enhance glucose and LCFA uptake, respectively. $\mathrm{Ca}^{2+} /$ calmodulinactivated kinase kinase- $\beta$ (CaMKK $\beta)$ has been positioned directly upstream of AMPK. However, it is unknown whether acute increases in $\left[\mathrm{Ca}^{2+}\right]_{\mathrm{i}}$ stimulate translocation of GLUT4 and CD36 and uptake of glucose and LCFA or whether $\mathrm{Ca}^{2+}$ signaling converges with AMPK signaling to exert these actions. Therefore, we studied the interplay between $\mathrm{Ca}^{2+}$ and AMPK signaling in regulation of cardiomyocyte substrate uptake. Exposure of primary cardiomyocytes to inhibitors or activators of $\mathrm{Ca}^{2+}$ signaling affected neither AMPK-Thr ${ }^{172}$ phosphorylation nor basal and AMPK-mediated glucose and LCFA uptake. Despite their lack of an effect on substrate uptake, $\mathrm{Ca}^{2+}$ signaling activators induced GLUT4 and CD36 translocation. In contrast, AMPK activators stimulated GLUT4/CD36 translocation as well as glucose/LCFA uptake. When cardiomyocytes were cotreated with $\mathrm{Ca}^{2+}$ signaling and AMPK activators, $\mathrm{Ca}^{2+}$ signaling activators further enhanced AMPK-induced glucose/LCFA uptake. In conclusion, $\mathrm{Ca}^{2+}$ signaling shows no involvement in AMPK-induced GLUT4/CD36 translocation and substrate uptake but elicits transporter translocation via a separate pathway requiring CaMKK $\beta$ / CaMKs. $\mathrm{Ca}^{2+}$-induced transporter translocation by itself appears to be ineffective to increase substrate uptake but requires additional AMPK activation to effectuate transporter translocation into increased substrate uptake. $\mathrm{Ca}^{2+}$-induced transporter translocation might be crucial under excessive cardiac stress conditions that require supraphysiological energy demands. Alternatively, $\mathrm{Ca}^{2+}$ signaling might prepare the heart for substrate uptake during physiological contraction by inducing transporter translocation.
\end{abstract}

$\mathrm{Ca}^{2+} /$ calmodulin-activated kinases; AMP-activated protein kinase; glucose transporter 4; CD36; cardiomyocytes

CARDIAC MUSCLE MEETS ITS ENERGY DEMANDS predominantly by uptake of glucose $(20-30 \%)$ and long-chain fatty acids (LCFA; 60-70\%) from the circulation. Whereas GLUT4 has been established to be the major cardiac glucose transporter for more than 20 years $(50)$, the heart is known to express several

Address for reprint requests and other correspondence: J. J. F. P. Luiken, Maastricht University, Dept. of Molecular Genetics, Cardiovascular Research Institute Maastricht (CARIM), P. O. Box 616, 6200 MD Maastricht, The Netherlands (e-mail: j.luiken@maastrichtuniversity.nl).
LCFA transporters, including CD36, fatty acid transport protein (FATP)1, and FATP6 (14). From these transporters, CD36 appeared to be quantitatively the most important one based on studies using the specific CD36 inhibitor sulfo- $N$-succinimidyloleate (33) and using CD36-knockout mice (20). Additionally, humans with CD36 deficiency show a nearly complete loss of myocardial LCFA uptake (35). Hence, during the continuous contractile activity of the heart, glucose and LCFA are taken up mainly into cardiomyocytes via GLUT4 and CD36, respectively $(14,31)$. We and others have shown that enhanced cardiac contraction leads to the simultaneous translocation of GLUT4 and CD36 from endosomal compartments to the sarcolemma to increase substrate entry $(7,14,32)$.

With respect to the signaling mechanisms involved in contraction-induced GLUT4 and CD36 translocation in cardiomyocytes, there is solid evidence for the involvement of AMPactivated protein kinase (AMPK), especially the AMPK $\alpha 2$ isoform $(21,32)$. Following a rise in subcellular AMP, the binding of AMP to AMPK makes this kinase conformationally accessible for phosphorylation by an AMPK kinase at $\mathrm{Thr}^{172}$ so that it will become activated (15). AMP also protects AMPK from dephosphorylation at $\mathrm{Thr}^{172}$, thus decelerating its deactivation (15). In cardiomyocytes from LKB1-null mice, contraction-induced GLUT4 and CD36 translocation was abolished, disclosing LKB1 as the responsible upstream kinase of AMPK (21). Activation of AMPK results in a series of signaling events, such as Akt substrate of $160 \mathrm{kDa}$ (AS160) phosphorylation causing GLUT4 and CD36 translocation $(39,40)$ and a consequential increase in substrate uptake. Additionally, AMPK activation increases glucose and LCFA oxidation through phosphorylation of glycolytic enzymes and of acetylCoA carboxylase (ACC), respectively (27).

Besides regulating AMPK activity, the continuous contractions of the heart also regulate the reoccurring $\mathrm{Ca}^{2+}$ transients. A rise of the cytoplasmic $\mathrm{Ca}^{2+}$ concentration $\left(\left[\mathrm{Ca}^{2+}\right]_{\mathrm{i}}\right)$ in each excitation-contraction coupling of the heart and also of skeletal muscle stimulates $\mathrm{Ca}^{2+}$-dependent signaling events such as activation of $\mathrm{Ca}^{2+} /$ calmodulin-dependent kinases through binding of $\mathrm{Ca}^{2+}$ to its carrier protein calmodulin. The binding of the $\mathrm{Ca}^{2+}$ /calmodulin complex to the CaM domain of $\mathrm{Ca}^{2+}$ / calmodulin-activated protein kinase kinases (CaMKKs) and of $\mathrm{Ca}^{2+} /$ calmodulin-activated protein kinase (CaMK)II releases the autoinhibition and leads to further activation of these Ser/Thr protein kinases. Activated CaMKK phosphorylates and activates its downstream target CaMKI. There are two isoforms of CaMKK, of which only CaMKK $\beta$ is highly expressed in the heart. Under normal physiological conditions, 
$\left[\mathrm{Ca}^{2+}\right]_{i}$ in the heart is finely regulated and the activity of CaMKs regulated by protein phosphatases in concert with $\left[\mathrm{Ca}^{2+}\right]_{\mathrm{i}}(3,6,8)$. Despite the fact that both CaMKK and CaMKII are activated in response to a cytoplasmic $\mathrm{Ca}^{2+}$ rise via a $\mathrm{Ca}^{2+}$ /calmodulin-dependent manner, it has been shown in skeletal muscle that both kinases also have autonomous activity $(16,38)$. Additionally, it was reported that exercise leads to rapid activation and increased phosphorylation of CaMKII and its downstream targets (37). However, the degree of autonomous activity of both CaMKKs and CaMKs, the speed of their activation, and the duration of their active states have not yet been reported for heart tissue.

Studies describing the role of $\mathrm{Ca}^{2+}$ signaling in skeletal muscle substrate uptake often have used caffeine to increase $\left[\mathrm{Ca}^{2+}\right]_{\mathrm{i}}(1,48)$. Specifically, it has been shown that caffeine treatment induces CaMKK $\beta$ and CaMKII phosphorylation concomitantly with increased glucose uptake. This caffeineinduced glucose uptake was sensitive to pharmacological CaMKK $\beta$ and CaMKII inhibition (48). Moreover, contractioninduced glucose uptake was at least partly inhibited by CaMKK $\beta$ and CaMKII inhibitors, which was indicative of a role for both $\mathrm{Ca}^{2+}$-activated kinases in contraction-induced glucose uptake (48). Contraction-induced LCFA uptake also appeared to be inhibited by CaMKK $\beta$ inhibition in skeletal muscle (2), whereas CaMKII inhibition has not yet been studied in this respect.

In contrast to skeletal muscle, information is lacking about the roles of CaMKK $\beta$ and CaMKII in contraction-induced substrate uptake in the heart, especially in relation to AMPK. A possible bridge between $\mathrm{Ca}^{2+}$ signaling and AMPK signaling might be provided by CaMKK $\beta$, because it is one of the kinases known to have AMPK kinase activity in vitro and to activate AMPK in mammalian cells deficient in $\operatorname{LKB} 1(25,47)$. Indeed, several studies in skeletal muscle indicate that CaMKK $\beta$ and CaMKII stimulate muscle substrate uptake through AMPK activation $(2,28)$. However, other data suggest that this $\mathrm{Ca}^{2+}$-induced signaling axis stimulates substrate uptake independently of AMPK $(46,48)$. Therefore, the aim of this study was to investigate the interrelation between AMPK, CaMKs, and $\left[\mathrm{Ca}^{2+}\right]_{\mathrm{i}}$ in the regulation of transporter-mediated substrate uptake into cardiomyocytes. To assess separately the effects of $\left[\mathrm{Ca}^{2+}\right]_{i}$ and of CaMKK $\beta / C a M K s$ on AMPK-mediated substrate uptake, we used pharmacological agents to activate these signaling pathways individually and independently from contraction.

\section{MATERIALS AND METHODS}

\section{Animals}

Rats were maintained at the Experimental Animal Facility of Maastricht University. All study protocols involving the rat experiments were approved by the Animal Care and Use Committee of Maastricht University and were performed according to the official rules formulated in the Dutch law on care and use of experimental animals, which are highly similar to those of the US National Institutes of Health (NIH Publication No. 85-23, revised 1996).

\section{Materials}

2-Deoxy-D- $\left[1-{ }^{3} \mathrm{H}\right]$ glucose and $\left[1-{ }^{14} \mathrm{C}\right]$ palmitic acid were obtained from GE Healthcare (Piscataway, NJ). Bovine serum albumin (BSA; fraction $\mathrm{V}$, essentially fatty acid free), laminin, phloretin, DMSO, thapsigargin, A23187, STO-609, KN93, oligomycin, 5-amino-1- $\beta$-D- ribofuranosyl-imidazole-4-carboxamide (AICAR), and adenine 9- $\beta$ D-arabinofuranoside (ara-A) were obtained from Sigma Aldrich (St. Louis, MO). Sulfo-NHS-LC-biotin and immobilized streptavidin were from Perbio Science (Etten-Leur, The Netherlands). Compound $\mathrm{C}$ was from Calbiochem (Radnor, PA). Fluo-4 acetoxy-methylester and pluronic acid $(\mathrm{F} 1420 \mathrm{c} 1)$ were from Invitrogen (Bleiswijk, The Netherlands).

\section{Antibodies}

Antibodies were purchased as indicated: phospho-ACC ( $\operatorname{Ser}^{79}$; no. 07-303) from Upstate (Billerica, MA); phospho-AMPK $\alpha$ (Thr ${ }^{172}$; no. 2531), phospho-AS160 (Thr ${ }^{642}$; no. 4288), and phospho-CaMKII (Thr ${ }^{286}$; no. 3361) from Cell Signaling Technology (Beverly, MA); phospho-CaMKI (sc-28438-R) from Santa Cruz Biotechnology (Santa Cruz, CA); caveolin-3 (no. 610420) from BD Transduction Laboratories (Franklin Lakes, NJ); anti-CD36 antibody (CRF D-2717) used in 2-photon microscopic images from BD Pharmingen (Franklin Lakes, NJ); and anti-GLUT4 (Ab 1346) used in Western Blotting from Chemicon International (Billerica, MA). FITC-labeled rabbit anti-mouse IgA secondary antibody was from from Rockland Immunochemical (Gilbertsville, PA). The anti-CD36 antibody (no. MO25) used in Western blotting was a gift from Dr. N. Tandon (Bethesda, MD).

\section{Isolation of Primary Rat Cardiomyocytes}

Adult rat cardiomyocytes (Lewis rats; $200-250$ g, 2-3 mo of age) were isolated by using a Langendorff perfusion system according to the procedure developed by Fischer et al. (12), as has been described previously (33). This method yields mainly ventricular myocytes. A modified Krebs-Henseleit bicarbonate (MKR) medium was stored at a 10 -fold concentration and contained $1.17 \mathrm{M} \mathrm{NaCl}, 26 \mathrm{mM} \mathrm{KCl}, 12$ $\mathrm{mM} \mathrm{KH} \mathrm{PO}_{4}, 12 \mathrm{mM} \mathrm{MgSO} 4,100 \mathrm{mM} \mathrm{NaHCO}$, and $100 \mathrm{mM}$ HEPES. Upon 10-fold dilution of the concentrated stock for daily use, the MKR medium was adjusted to $\mathrm{pH} 7.55$ and equilibrated with a $95 \% \mathrm{O}_{2}-5 \% \mathrm{CO}_{2}$ gas phase at $37^{\circ} \mathrm{C}$.

\section{Experiments With Primary Cardiomyocytes}

To recover from the isolation procedure, cardiomyocytes were incubated for an additional $90 \mathrm{~min}$ in medium $A(1 \times$ MKR medium supplemented with $2 \% \mathrm{BSA}, 2 \mathrm{mM}$ D-glucose, and $1 \mathrm{mM} \mathrm{CaCl}_{2}$ ) while rotating at room temperature $\left(24^{\circ} \mathrm{C}\right)$. For substrate uptake measurements $\sim 200,000$ cells/condition were used, and for signaling experiments $\sim 100,000$ cells/condition were used. During these experiments, cell suspensions were incubated with/without stimulators and/or inhibitors of $\mathrm{Ca}^{2+}$ and AMPK signaling in capped 20-ml glass vials. The vials were placed in a $37^{\circ} \mathrm{C}$ water bath under continuous shaking at $160 \mathrm{rpm}$.

\section{Measurement of 2-Deoxy-[1- $\left.{ }^{3} \mathrm{H}\right]$ glucose and $\left[1-{ }^{14} \mathrm{C}\right]$ palmitate Uptake Rates Into Cardiomyocytes}

To increase $\left[\mathrm{Ca}^{2+}\right]_{\mathrm{i}}$ and also activate CaMKs, cardiomyocytes were exposed to $5 \mu \mathrm{M}$ A23187 or $5 \mu \mathrm{M}$ thapsigargin for $20 \mathrm{~min}$. For AMPK activation, cardiomyocytes were treated with either oligomycin $(5 \mu \mathrm{M})$ or AICAR $(1.5 \mathrm{mM})$ for 20 min or subjected to $4-\mathrm{Hz}$ electric field stimulation during the last $7 \mathrm{~min}$ of a 20 -min total of incubation time. For inhibition of CaMKs by STO-609 $(5 \mu \mathrm{M})$ or KN93 $(5 \mu \mathrm{M})$, cardiomyocytes were preincubated for $20 \mathrm{~min}$, whereafter either CaMKs or AMPK activating stimuli were added for an additional $20 \mathrm{~min}$. Subsequently, substrate uptake was measured by the addition of $0.5 \mathrm{ml}$ of a mixture of a 2-deoxy-[1- $\left.{ }^{3} \mathrm{H}\right]$ glucose and $\left[1-{ }^{14} \mathrm{C}\right]$ palmitate/BSA complex, as described previously (33). Five minutes after the addition of the radiolabeled substrates, the uptake reaction was stopped by transferring the cell contents to 15-ml Falcon tubes containing ice-cold MKR buffer with $0.1 \%$ BSA and $0.2 \mathrm{mM}$ phloretin (stop solution). Cells then were washed two times for $2 \mathrm{~min}$ 
at $45 \mathrm{~g}$ in ice-cold stop solution, as described previously (33). The radioactivity of the cell pellets was measured by scintillation counting.

\section{Measurements of $\left[\mathrm{Ca}^{2+}\right]_{i}$}

Freshly isolated cardiomyocytes were plated in laminin-coated 12-well plates in medium A. Cardiomyocytes were allowed to attach to the bottom of each well for 90 min before loading with $5 \mu \mathrm{M}$ fluo-4 acetoxymethyl ester (AM) and $2 \mathrm{mg} / \mathrm{ml}$ pluronic F-127 for $30 \mathrm{~min}$. After a 15-min period to allow probe deesterification, the fluo-4loaded cells were washed three times with medium $A$. The washed cells in the 12 -well plate were subjected to $\mathrm{Ca}^{2+}$ measurements by pseudo-ratio fluorescence microscopic imaging using a filter wheel-controlled Nikon Diaphot 200 microscope equipped with a Hamamatsu EM-CCD digital camera and VitiTech (Sunderland, UK) image control software (26). Fluorescence image recordings at $0.5 \mathrm{~Hz}$ from microscopic fields (capturing for $20 \mathrm{~ms}$ ) containing at least 15 cardiomyocytes were performed during the addition of thapsigargin, A23187, or oligomycin (each at $5 \mu \mathrm{M}$ ) at the indicated time periods. Where indicated, cardiomyocytes were subjected to electric field stimulation at a frequency of $4 \mathrm{~Hz}$; image recording was at 0.24 -s time intervals. Fluo-4 fluorescence was analyzed per region of interest per image, representing a single cell, and corrected for background (adjacent regions of interest not representing a cell). Changes in fluorescence per region of interest were converted to pseudo-ratio values $F^{\prime}=F / F_{o}$, where $F$ is the measured fluorescence value, $F_{o}$ is the average fluorescence level for $20 \mathrm{~s}$ under resting conditions, and $\mathrm{F}^{\prime}$ is the pseudo-ratio fluorescence level at any time (4).

\section{Surface Detection of GLUT4 and CD36}

Three distinct methods were used to assess cellular surface presence of GLUT4 and CD36.

Biotinylation method. The biotinylation technique was used to separate plasma membrane proteins from subcellular proteins. After isolation, cardiomyocytes were plated on laminin-coated $(10 \mu \mathrm{g} / \mathrm{ml})$ 35-mm culture plates. After a 90-min attachment, cells were incubated with stimuli and subsequently biotinylated with the cell-impermeable reagent sulfo-NHS-LC-biotin in $1 \times$ MKR medium at a final concentration of $1 \mathrm{mg} / \mathrm{ml}$ for $45 \mathrm{~min}$ at $4{ }^{\circ} \mathrm{C}$, as described previously (43). Thereafter, cells were treated with ice-cold glycine $(100 \mathrm{mM})$ in $1 \times$ MKR medium. After a brief wash with ice-cold $1 \times$ MKR medium, cells were scraped in $300 \mu \mathrm{l}$ of lysis buffer [consisting of $50 \mathrm{mM}$ Tris. $\mathrm{HCl}, 150 \mathrm{mM} \mathrm{NaCl}, 1 \%$ (vol/vol) Igepal CA-630 (or NP-40), 5\% (wt/vol) sodium deoxycholate, $1 \%$ (wt/vol) SDS, $4 \%$ (vol/vol) complete protease inhibitor cocktail, 5\% PhosSTOP phosphatase inhibitor cocktail]. The lysates were rotated for $1 \mathrm{~h}$ at $4^{\circ} \mathrm{C}$ and centrifuged for $10 \mathrm{~min}$ at $13,000 \mathrm{~g}$ at $4^{\circ} \mathrm{C}$. Thirty microliters of supernatant was used for detecting total protein samples with Western blotting, and $150 \mu \mathrm{l}$ of supernatant was incubated overnight with streptavidin beads. Samples then were centrifuged for $2 \mathrm{~min}$ at $13,000 \mathrm{~g}$ at $4^{\circ} \mathrm{C}$. Thereafter, beads were washed twice with lysis buffer. The biotinylated proteins were eluted by incubation of the streptavidin beads for 5 min at $95^{\circ} \mathrm{C}$ in sample buffer (40\% glycerol, $0.25 \mathrm{M}$ Tris, $1 \mathrm{M}$ DTT, bromophenol blue). Samples were subjected to SDS polyacrylamide gel electrophoresis, followed by Western blotting for the detection of GLUT4 and C36.

Fractionation method. After recovery, cardiomyocytes were pretreated for 20 min with kinase inhibitors STO-609 and KN93 and subsequently stimulated with the indicated agonist for $15 \mathrm{~min}$. Thereafter, cell suspensions were subjected to the fractionation procedure, as described previously (32). GLUT4 and CD36 proteins were detected by Western blotting.

Two-photon microscopy. Following a 10-min pretreatment with either A23187, thapsigargin, or oligomycin, cells were labeled for 10 min with $2 \mu \mathrm{g} / \mathrm{ml}$ (diluted in medium A) anti-CD36 antibody. Subsequently, FITC-labeled rabbit anti-mouse IgA secondary antibody $\left(\mathrm{C}_{\text {end }}\right.$ 1:500) was added to the cells. Finally, cardiomyocytes were washed twice with medium A. Viable cardiomyocytes were imaged using a Leica SP5 Multiphoton imaging platform (Leica Microsystems). The excitation wavelength of the $140 \mathrm{fs}$-pulsed laser was 800 $\mathrm{nm}$, whereas emission filters were optimized for FITC detection $(500-560 \mathrm{~nm})$. Laser power was kept as low as possible to avoid bleaching and photo damage. Because antibodies do not have access to the cellular interior in these intact cardiomyocytes, only cell surface CD36 will be stained. For quantification of the cell surface staining, images were processed with ImageJ software (JAVA-based imaging software from the National Institutes of Health). Cardiomyocytes were kept at $37^{\circ} \mathrm{C}$ during incubations and imaging.

\section{Statistics}

Differences among the data obtained from five to eight experiments are presented as means \pm SE. Statistical differences between groups of observations were evaluated by unpaired Student's $t$-test, one-way ANOVA, and/or two-way ANOVA, depending on the groups compared, by using statistical analysis software Prism 5 (GraphPad Software). A $P$ value $\leq 0.05$ was considered statistically significant.

\section{RESULTS}

Testing the Potential of Thapsigargin and A23187 as $\left[\mathrm{Ca}^{2+}\right]_{i}$ Elevating Agents and STO-609 and $\mathrm{KN93}$ as $\mathrm{Ca}^{2+}$ Signaling Inhibitors in Cardiomyocytes

Fluorescent $\mathrm{Ca}^{2+}$ indicators are suitable tools for studying $\mathrm{Ca}^{2+}$ transients in primary adult cardiomyocytes (23). In the present study, cardiomyocytes isolated from adult rats were adhered in 12-well plates and loaded with the $\mathrm{Ca}^{2+}$ probe fluo-4 to measure single-cell $\left[\mathrm{Ca}^{2+}\right]_{\mathrm{i}}$ transients by microscopic fluorescence imaging. We used two agents with different action mechanisms, i.e., the sarco/endoplasmic reticulum $\mathrm{Ca}^{2+}$-ATPase inhibitor thapsigargin and the $\mathrm{Ca}^{2+}$ ionophore A23187, to study the effects of increased $\left[\mathrm{Ca}^{2+}\right]_{\mathrm{i}}$. Each of these agents was used at $5 \mu \mathrm{M}$, in agreement with previous studies in myocytes $(24,44)$. Under resting conditions, in the absence of electrical field stimulation, the majority of cells displayed incidental $\mathrm{Ca}^{2+}$ transients (Fig. 1), which paralleled spontaneous contractions of the cells. In fluo-4-loaded cells treated with the ATP synthase inhibitor oligomycin, the frequency of the $\mathrm{Ca}^{2+}$ transients increased threefold. In these oligomycin-treated cells, as well as in cells exposed to $4-\mathrm{Hz}$ electrostimulation, levels of $\left[\mathrm{Ca}^{2+}\right]_{\mathrm{i}}$ fully restored to basal levels in between each transient (Fig. 1). In contrast, stimulation of the cells with either thapsigargin or A23187 provoked marked and prolonged increases in $\left[\mathrm{Ca}^{2+}\right]_{\mathrm{I}}$, not restoring to baseline values within $5 \mathrm{~min}$. At these concentrations, A23178 and thapsigargin did not affect short-term cell survival, as the rod-shaped appearance of the cardiomyocytes was not altered by these treatments (Fig. 1).

Compatible with their ability to increase $\left[\mathrm{Ca}^{2+}\right]_{i}$, thapsigargin and A23187 enhanced phosphorylation of CaMKI (1.6and 2.2-fold, respectively) and of CaMKII (1.4- and 1.6-fold, respectively) (Fig. 2A). A23187-induced CaMKI phosphorylation was significantly inhibited by the CaMKK $\beta$ inhibitor STO-609 but not by the CaMKII inhibitor KN93 (Fig. 2A). In contrast, A23187-induced CaMKII phosphorylation was significantly inhibited by KN93 but not by STO-609 (Fig. 2A). Both inhibitors were used at $5 \mu \mathrm{M}$, in agreement with previous cell studies $(25,45)$. We did not observe an increased phosphorylation of CaMKI or of CaMKII upon 7-min, 4-Hz stimulation (Fig. 2B), which is in contrast to findings in skeletal 
Control

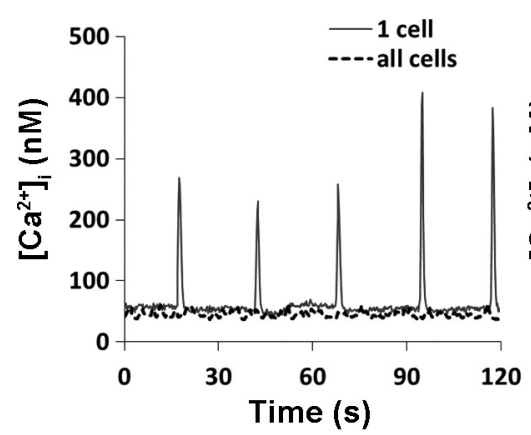

Thapsigargin
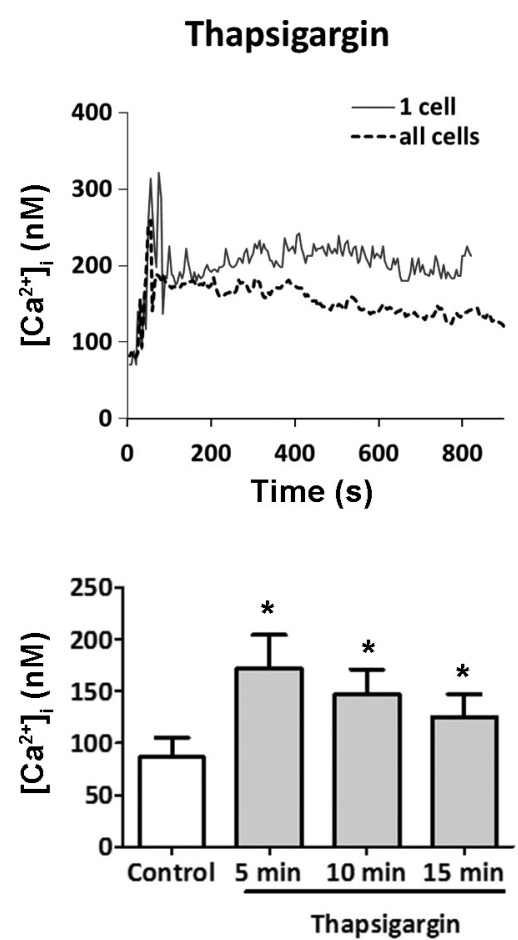

Oligomycin

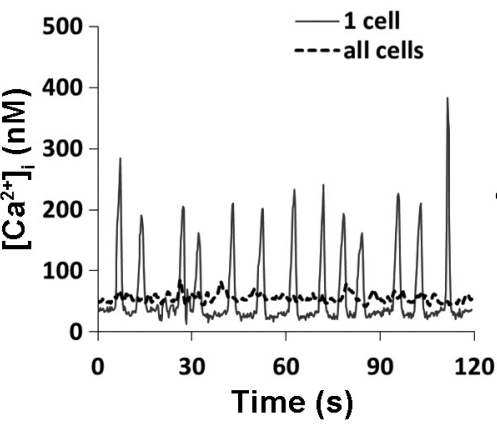

A23187
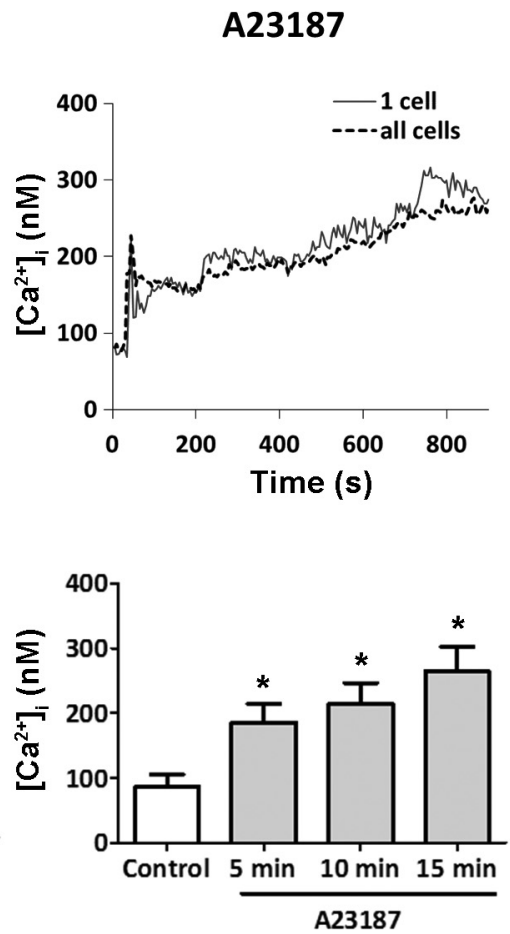

$4 \mathrm{~Hz}$ electrostimulation

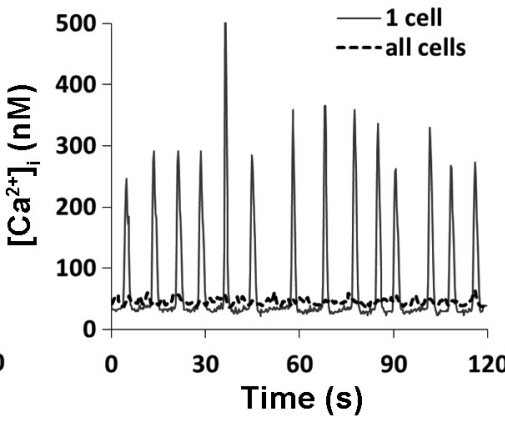

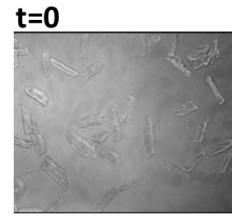

$\mathrm{t}=\mathbf{1 5} \min$

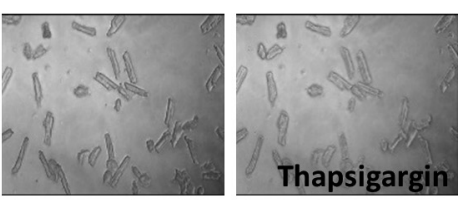

Fig. 1. Thapsigargin and A23187 induce elevation of $\left[\mathrm{Ca}^{2+}\right]_{\mathrm{i}}$ in cardiomyocytes. For measurement of $\left[\mathrm{Ca}^{2+}\right]_{i}$, immobilized primary cardiomyocytes loaded with fluo-4 were exposed to oligomycin $(5 \mu \mathrm{M})$, electrostimulation $(4 \mathrm{~Hz})$, thapsigargin $(5 \mu \mathrm{M})$, or A23187 $(5 \mu \mathrm{M})$ for the times indicated. Traces are from representative cells; averaged traces are from 30 to 40 cells. At the concentrations used, A23187 or thapsigargin did not affect cell viability, as indicated by the microscopical images taken at 0 and $15 \mathrm{~min}$.*Vs. control $(P<0.05)$.

muscle $(1,48)$. Additionally, treatment with oligomycin or AICAR treatment did not increase phosphorylation of either kinase (Fig. 2B).

We conclude that thapsigargin and A23187 increase $\left[\mathrm{Ca}^{2+}\right]_{\mathrm{i}}$, thereby activating both CaMKK $\beta$ - and CaMKII-dependent signaling events in cardiomyocytes. Furthermore, $\mathrm{Ca}^{2+}$ signaling remains unchanged in response to oligomycin or AICAR, indicating their specificity for AMPK activation in our cellular model. Also, the inhibitors STO-609 and KN93 block their intended target enzymes CaMKK $\beta$ and CaMKII, respectively.

Effects of $\mathrm{Ca}^{2+}$ Signaling Inhibitors on AMPK Activation and on AMPK-Mediated Substrate Uptake in Cardiomyocytes

We investigated the roles of CaMKK $\beta$ and CaMKs in AMPK activation and in AMPK-mediated substrate uptake into cardiomyocytes. To activate AMPK in cardiomyocytes, we used both a pharmacological approach (oligomycin or AICAR) and a physiological approach (4-Hz electrostimulation). Each of these treatments induced AMPK-Thr ${ }^{172}$ phosphorylation (7.4-, 6.2-, and 2.9 -fold, respectively) and, concomitantly, phosphorylation of AMPK's major substrate ACC at $\operatorname{Ser}^{97}$ (10-, 8-, and 3-fold, respectively) (Fig. 3A), in agreement with our previous observations $(32,34)$. Correspondingly, all three AMPK activators enhanced palmitate uptake significantly (1.7-, 1.3-, and 1.4-fold, respectively). Additionally, oligomycin and $4-\mathrm{Hz}$ electrostimulation enhanced deoxyglucose uptake (2.2- and 1.4-fold, respectively), whereas AICAR showed no effect (Fig. $3 A$ ). The inability of AICAR to induce glucose uptake is in agreement with our previous observations $(10,19,33)$ and relates to the fact that, next to AMPK activation, glucose uptake requires 
A

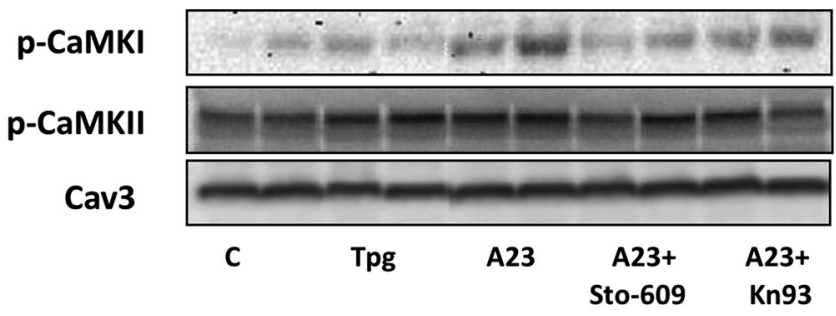

Phospho-CaMKI (Thr 177)

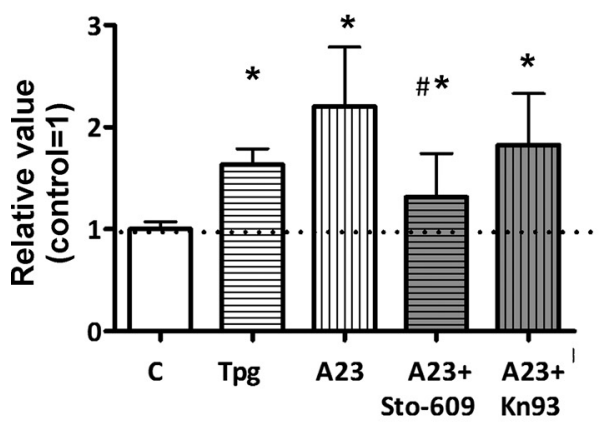

Phospho-CaMKII (Thr286)

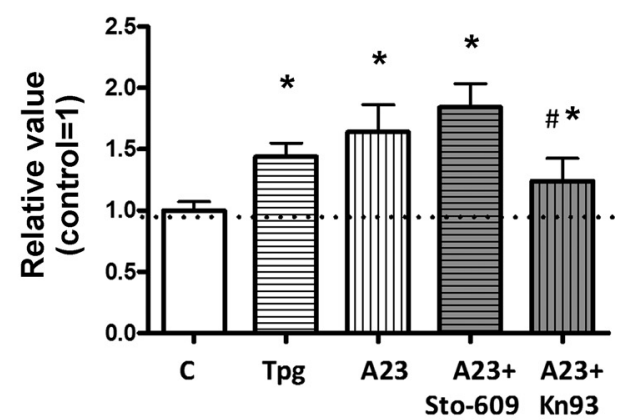

B

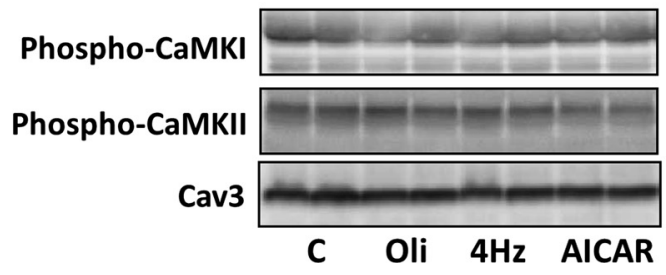

additional activation of protein kinase D1. As a result, AICAR, which in contrast to oligomycin or $4-\mathrm{Hz}$ stimulation does not activate protein kinase D1, can only be used to study AMPK-mediated LCFA uptake (10). Pretreatment of cardiomyocytes with STO-609 or KN93 did not alter AMPK-Thr ${ }^{172}$ and ACC-Ser ${ }^{97}$ phosphorylation induced by all three AMPK-activating stimuli (Fig. 3A). Furthermore, pretreatment with either of these inhibitors did not alter the effect of each of the three AMPK-activating stimuli on deoxyglucose or palmitate uptake (Fig. 3B).

In conclusion, $\mathrm{Ca}^{2+}$ signaling does not appear to be involved in either in AMPK activation or in AMPK-mediated substrate uptake into cardiomyocytes.

\section{Effects of $\mathrm{Ca}^{2+}$-Elevating Stimuli on GLUT4 and CD36 Translocation in Cardiomyocytes}

To investigate the effect of thapsigargin and A23187 on GLUT4 and CD36 translocation, we used three independent methods to monitor transporter translocation: cell surface biotinylation, subcellular fractionation, and immunolabeling. Immunolabeling of cell surface protein, in contrast to the other methods, can be employed only for CD36 and not for GLUT4 detection, because suitable GLUT4 antibodies that are capable of recognizing the cell surface epitopes are lacking at present. First, we examined GLUT4 and CD36 translocation via cell surface biotinylation with sulfo-NHSLC-biotin, which binds to free amino groups of extracellularly exposed lysine residues. We have already applied this method successfully to monitor insulin-induced CD36 translocation in Chinese hamster ovary cells (43). This method is also suitable for detecting cell surface GLUT4, notwithstanding that GLUT4 expresses only a single extracellular lysine (at position 50). Accordingly, we (22) and others (11, 42) have shown that insulin stimulates the binding of sulfoNHS-LC-biotin to GLUT4. In the present study, oligomycin, a well-established inducer of GLUT4 and CD36 translocation (32), was used as positive control to validate the suitability of the cell surface biotinylation protocol and also of the other methods to detect surface GLUT4 and CD36. As shown in Fig. $4 A$, the biotinylation experiments showed that oligomycin, thapsigargin, and A23187 enhanced sarcolemmal contents of GLUT4 (1.3-fold each) and CD36 (1.8-, 2.1-, and 1.9-fold, respectively) (Fig. 4A). This increase in cell surface content of both transporters occurred in the absence of changes in overall protein expression of GLUT4 and CD36 (Fig. 4A). Using subcellular fractionation, we also detected an increased sarcolemmal content of GLUT4 (1.5-, 1.3-, and 1.4-fold, respectively) and of CD36 (1.5-, 1.7-, and 1.4-fold, respectively) upon treatment with each of these stimuli (Fig. 4B). This method further demonstrated a 


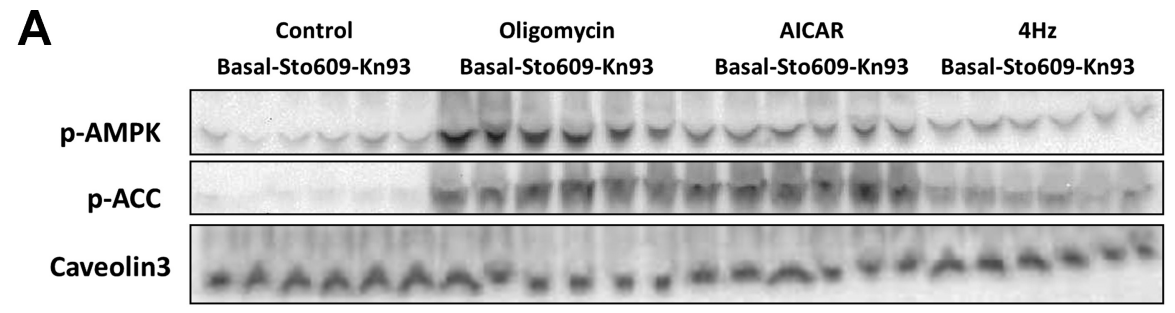

Fig. 3. Effects of STO-609 and KN93 on AMPK activation and AMPK-mediated substrate uptake into cardiomyocytes. Cardiomyocytes were preincubated for $15 \mathrm{~min}$ in the absence (C) or presence of STO-609 or KN93 and subsequently subjected to AMPK-activating stimuli (Oli; $5 \mu \mathrm{M} / 15 \mathrm{~min}$ ), AICAR (5 $\mathrm{mM} / 15 \mathrm{~min}$ ), and electric field stimulation (4 $\mathrm{Hz} / 7 \mathrm{~min}) . \quad A$ : activation of AMPK and acetyl-CoA carboxylase (ACC) was assessed by Western blotting. $B$ : uptake of 2-deoxy-[1$\left.{ }^{3} \mathrm{H}\right]$ glucose and $\left[1-{ }^{14} \mathrm{C}\right]$ palmitate/BSA complex $(5 \mathrm{~min})$ was determined as pelletable radioactivity. Values are displayed as means \pm SE $(n=5)$. *Vs. control $(P<0.05)$.
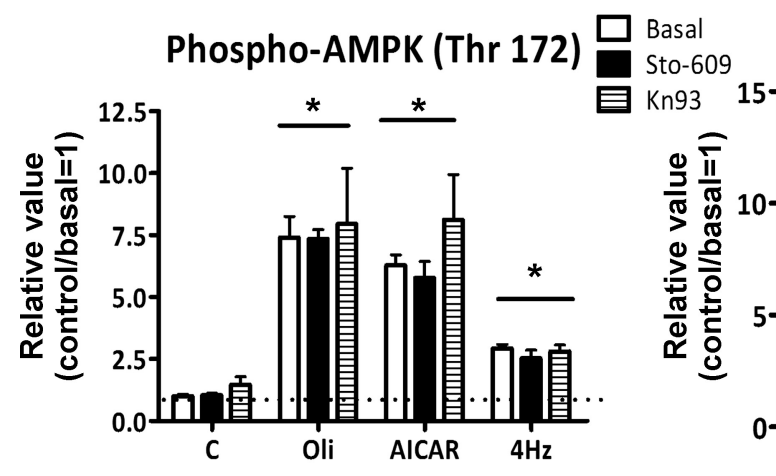

Phospho-ACC (Ser 79)
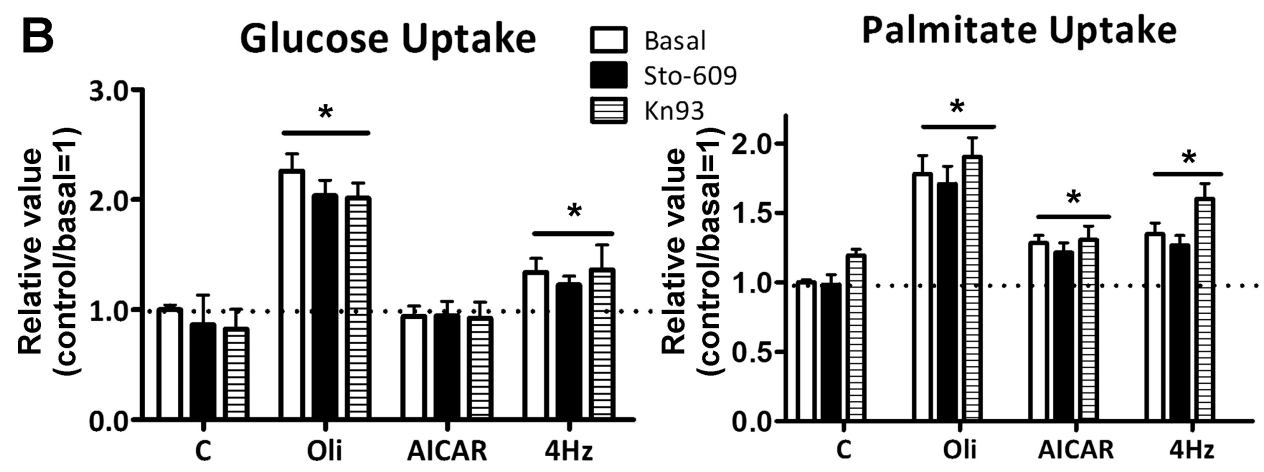

concomitantly decreased content of GLUT4 (by 40, 50, and $25 \%$, respectively) and of CD36 (by 50, 70, and 65\%, respectively) from the low-density microsomal fraction that represents intracellular membrane compartments (Fig. 4B). Finally, immunodetection and microscopical visualization of CD36 in intact cardiomyocytes clearly demonstrated increased cell surface staining upon treatment with each stimulus (Fig. 4C).

In conclusion, just as with oligomycin, the two applied $\mathrm{Ca}^{2+}$ raising agonists induce translocation of both GLUT4 and CD36 from intracellular membrane compartments to the sarcolemma.

\section{Effects of $\mathrm{Ca}^{2+}$-Elevating Stimuli on Substrate Uptake Into Cardiomyocytes}

Based on the observation that thapsigargin and/or A23187 induce GLUT4 and CD36 translocation, we studied whether transporter membrane localization results in increased glucose and LCFA uptake rates, respectively. In agreement with Fig. 3, $A$ and $B$, oligomycin potently induced AMPK$\mathrm{Thr}^{172}$ and ACC-Ser ${ }^{97}$ phosphorylation and also phosphorylation of AS160, another AMPK substrate (Fig. 5A), and markedly enhanced deoxyglucose and palmitate uptake into cardiomyocytes (Fig. 5B). However, thapsigargin and A23187 were without any effect on phosphorylation of AMPK and its substrates ACC and AS160 and also did not affect deoxyglucose and palmitate uptake (Fig. 5, $A$ and $B$ ). Together, these findings indicate that AMPK activation is not involved in $\mathrm{Ca}^{2+}$-induced GLUT4 and CD36 translocation and that $\mathrm{Ca}^{2+}$ induced translocation of both transporters as such is insufficient for increased glucose and/or LCFA uptake.

Apparently, $\mathrm{Ca}^{2+}$-induced GLUT4 and CD36 translocation did not effectuate into increased uptake. However, it is still possible that coactivation of AMPK might be required to reveal a stimulatory action of the $\left[\mathrm{Ca}^{2+}\right]_{i}$-raising agonists on glucose and LCFA uptake. For this purpose, we studied the effects of cotreatment of $\mathrm{Ca}^{2+}$ signaling activators with AMPK activators on AMPK signaling and on deoxyglucose and palmitate uptake. Thapsigargin and A23198, each unable to stimulate AMPK signaling by themselves, were also unsuccessful in further stimulating AMPK-Thr ${ }^{172}$, ACC-Ser ${ }^{97}$, and AS160$\mathrm{Thr}^{642}$ phosphorylation in oligomycin-treated cardiomyocytes (Fig. 5A). However, remarkably, thapsigargin and A23187, each unable to stimulate substrate uptake by themselves, enhanced deoxyglucose uptake significantly in the presence of oligomycin cotreatment (1.4- and 1.3-fold, respectively) and palmitate uptake in the presence of either oligomycin cotreatment (each 1.3-fold) (Fig. 5B). 
A

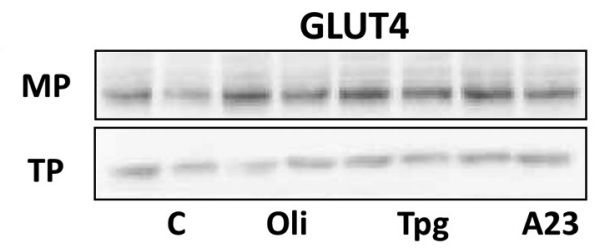

CD36

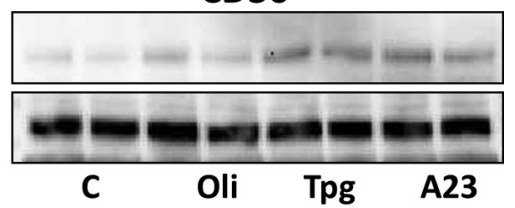

CD36

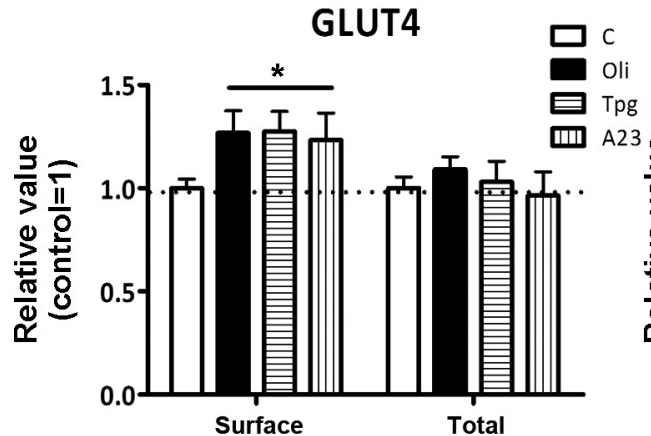

B
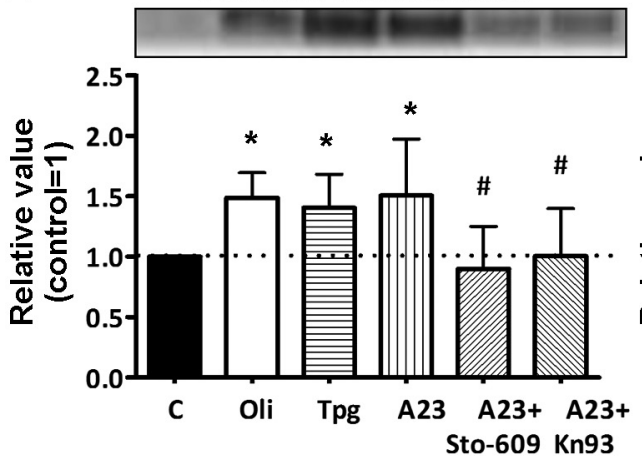

Low density microsomes

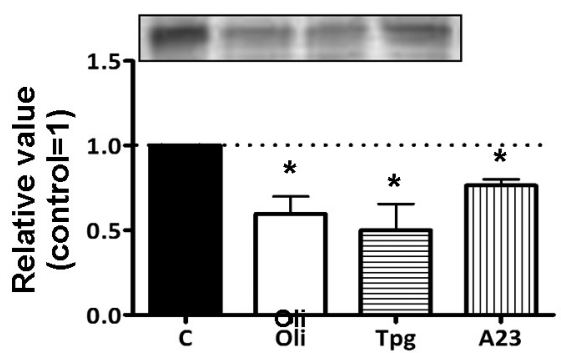

C Control Oligomycin
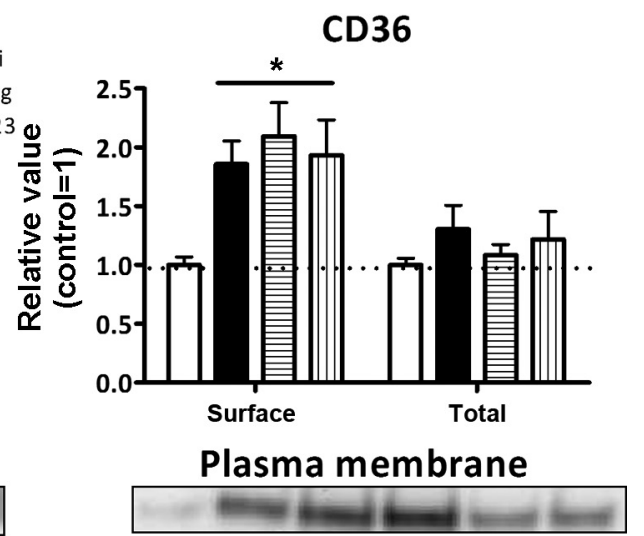

Low density microsomes

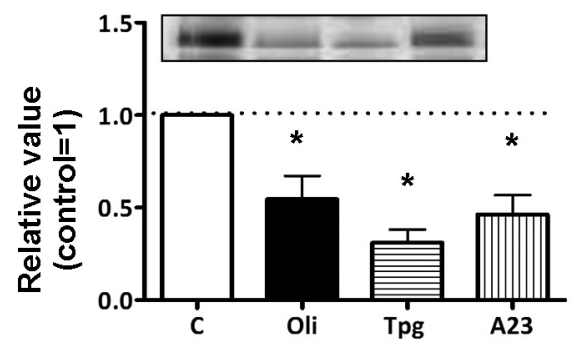

Thapsigargin $\quad$ A23187

Fig. 4. Effects of $\left[\mathrm{Ca}^{2+}\right]_{i}$-elevating agents on glucose transporter 4 (GLUT4) and CD36 translocation. Cardiomyocytes were preincubated for $15 \mathrm{~min}$ in the absence $(\mathrm{C})$ or presence of Tpg $(5 \mu \mathrm{M})$, A23 $(5 \mu \mathrm{M})$, or Oli $(5$ $\mu \mathrm{M}$, positive control). In selected experiments, cardiomyocytes were pretreated with STO-609 $(5 \mu \mathrm{M})$ or KN93 $(5 \mu \mathrm{M})$ for $15 \mathrm{~min}$ prior to addition of the $\left[\mathrm{Ca}^{2+}\right]_{\mathrm{i}}$-elevating stimuli. Following these treatments, cardiomyocytes were used for 3 different assays to detect transporter translocation. A: biotinylation assay; GLUT4 and CD36 were detected by Western blotting prior to biotinylation (total) and after biotinylation (surface). Signals were quantified using Quantity-One software $(n=5)$. Representative blots are shown. $B$ : fractionation method; in the collected plasma membrane and low-density microsomal fractions, GLUT4 and CD36 were detected by Western blotting and quantified $(n=5)$. Representative blots are shown. $C$ : 2-photon microscopy; CD36 was detected upon FITC labeling. Quantification of the CD36 signal was performed using ImageJ software $(n=5)$. Representative microscopical images are shown. Values are displayed as means \pm SE. *Vs. C; \#vs. A23 $(P<0.05)$. 
A on AMPK activation and substrate uptake into primary cardiomyocytes. Cardiomyocytes were incubated for $15 \mathrm{~min}$ in the absence (C) or presence of Tpg $(5 \mu \mathrm{M}), \mathrm{A} 23$ (5 $\mu \mathrm{M})$, or Oli $(5 \mu \mathrm{M})$. A: phosphorylation of AMPK, ACC, and Akt substrate of $160 \mathrm{kDa}$ (AS160) was assessed by Western blotting. $B$ : uptake of 2-deoxy- $\left[1-{ }^{3} \mathrm{H}\right]$ glucose and $[1-$ $\left.{ }^{14} \mathrm{C}\right]$ palmitate $(5 \mathrm{~min})$ was determined as pelletable radioactivity. Values are displayed as means $\pm \mathrm{SE}(n=5)$. *Vs. control $(P<0.05)$.

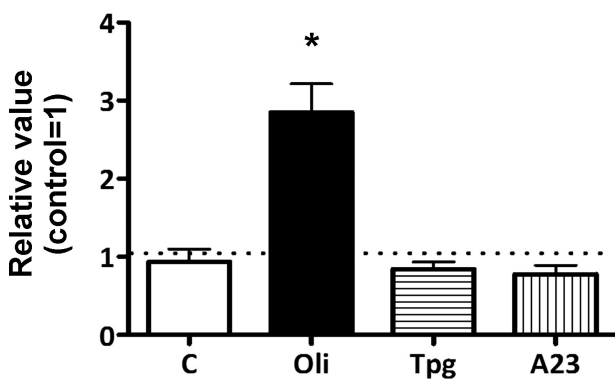

\section{Glucose Uptake}

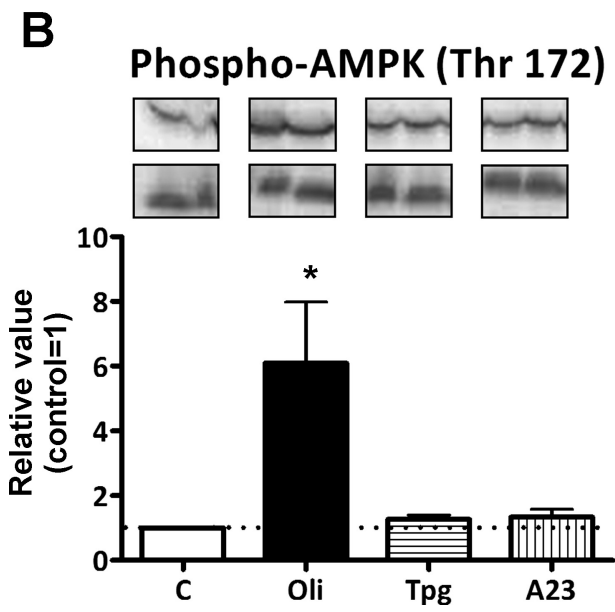

Palmitate Uptake

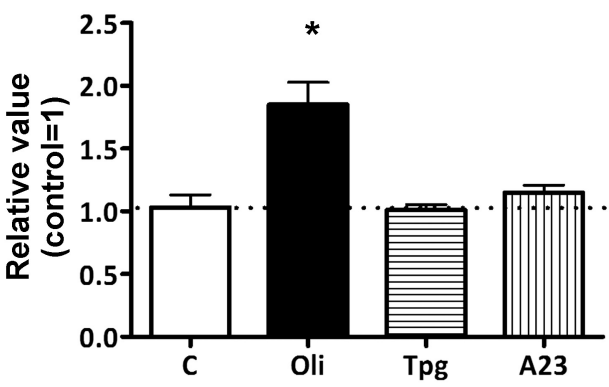

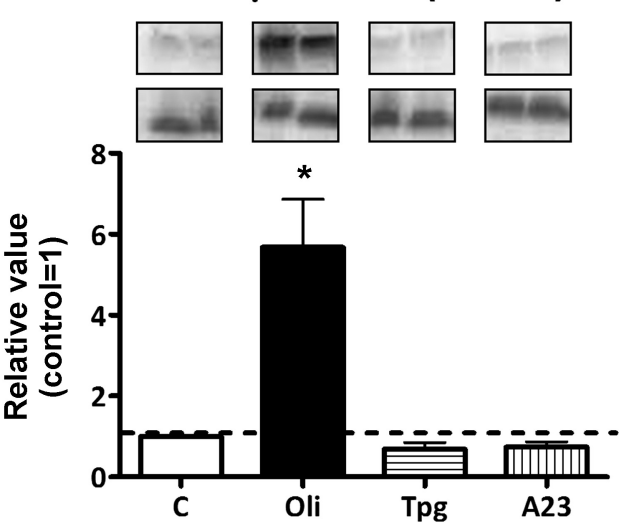

Effects of AMPK Inhibitors on Substrate Uptake Into Cardiomyocytes Treated With $\mathrm{Ca}^{2+}$ and AMPK Activators

To determine whether A23187-stimulated substrate uptake in the presence of AMPK coactivation was dependent on this AMPK coactivation and not due to off-target actions of the used AMPK activators, we incubated cardiomyocytes with established AMPK inhibitors, i.e., compound C and Ara-A. In the absence of these inhibitors, AICAR stimulated palmitate uptake 1.3-fold, and A23187 further stimulated palmitate uptake 1.3-fold, bringing the combined activation to 1.6-fold (Fig. 6A). As expected, each of these AMPK inhibitors successfully inhibited AICAR-induced AMPK-Thr ${ }^{172}$ and ACC$\mathrm{Ser}^{97}$ phosphorylation (Fig. 6B). Although compound $\mathrm{C}$ and Ara-A did not alter basal palmitate uptake, each agent completely inhibited AICAR-induced palmitate uptake (Fig. 6A). Furthermore, each agent completely inhibited A23187-stimulated palmitate uptake in the presence of AICAR cotreatment (Fig. 6A).

In conclusion, the ability of A23187 to increase deoxyglucose and palmitate uptake into cardiomyocytes in the presence of AMPK activators indicates that $\mathrm{Ca}^{2+}$-induced transporter translocation requires AMPK coactivation for effectuating such translocation into enhanced substrate uptake.

\section{DISCUSSION}

The aim of this study was to investigate the interrelation between $\left[\mathrm{Ca}^{2+}\right]_{i}, \mathrm{CaMKK} \beta / \mathrm{CaMKs}$, and AMPK in the shortterm regulation of substrate uptake into the heart. This shortterm regulation is mediated by translocation of GLUT4 and
CD36 to the cell surface. The major novel findings of this study are as follows: 1) $\mathrm{Ca}^{2+}$ signaling is not involved either in AMPK activation or in AMPK-mediated substrate uptake; 2) activation of $\mathrm{Ca}^{2+}$ signaling, similarly to AMPK signaling, stimulates translocation of GLUT4 and CD36 from endosomes to the sarcolemma; 3 ) in contrast, activation of $\mathrm{Ca}^{2+}$ signaling does not stimulate glucose or LCFA uptake, whereas AMPK signaling does; and finally, 4) $\mathrm{Ca}^{2+}$-induced translocation of GLUT4 and/or CD36 can result in enhanced substrate uptake when accompanied with AMPK activation.

Together, these findings propose that $\mathrm{Ca}^{2+}$-induced transporter translocation may help to recruit an additional quantity of substrate transporters to the sarcolemma to have these available to respond rapidly to conditions that require supraphysiological energy demands.

\section{$\mathrm{Ca}^{2+}$ Signaling is Not Involved in Either AMPK Activation or AMPK-Mediated Substrate Uptake}

In skeletal muscle, activation of $\mathrm{Ca}^{2+}$ signaling induces AMPK activation, and CaMKK $\beta$ appears to be involved in contraction-induced AMPK activation (2, 28). In contrast, in our cardiomyocyte studies the $\left[\mathrm{Ca}^{2+}\right]_{\mathrm{i}}$-increasing stimuli A23187 and thapsigargin did not alter AMPK activation. Moreover, neither STO-609 nor KN93 affected contractioninduced AMPK activation or AMPK activation by AICAR or oligomycin, thus excluding a role for $\mathrm{CaMKK} \beta$ or CaMKII in the regulation of AMPK signaling in the heart. The inability of CaMKII to activate AMPK in cardiomyocytes is in agreement with previous work in skeletal muscle (48). However, the lack 

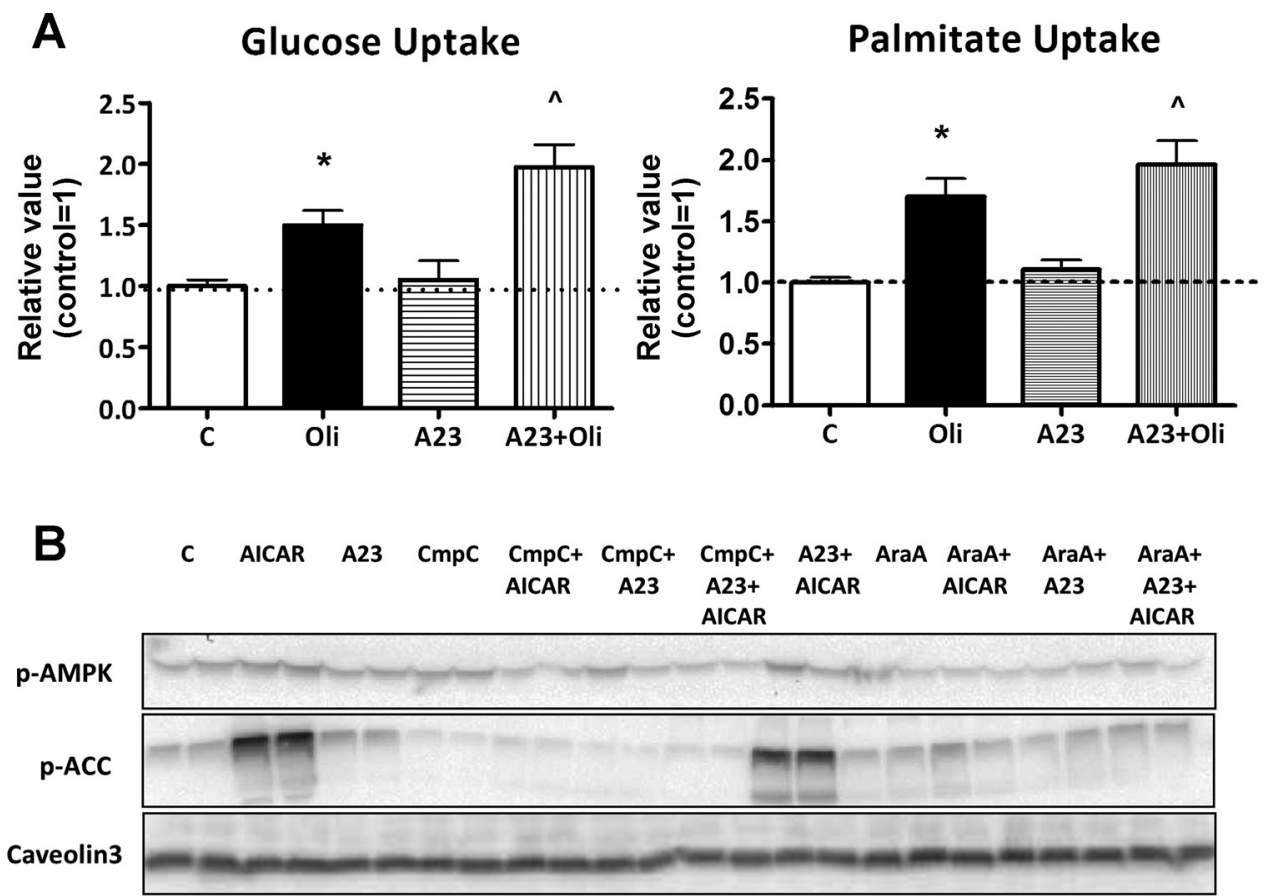

Palmitate Uptake

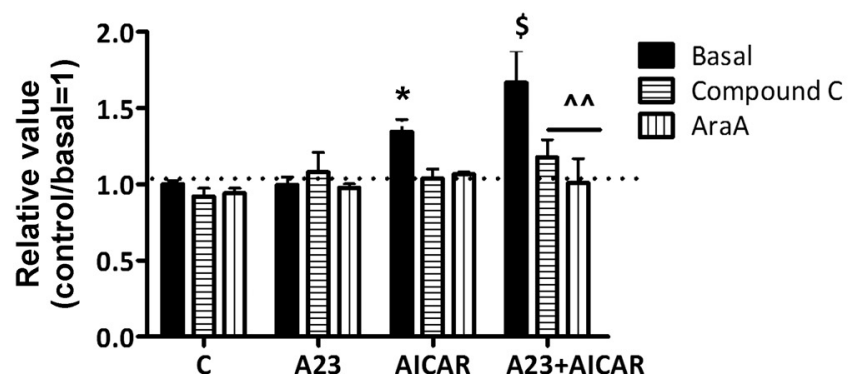

Fig. 6. Effects of AMPK inhibitors on substrate uptake into cardiomyocytes treated with $\mathrm{Ca}^{2+}$-elevating and/or AMPK-activating agents. Cardiomyocytes were incubated for $15 \mathrm{~min}$ in the absence $(\mathrm{C})$ or presence of adenine 9- $\beta$-D-arabinofuranoside (Ara-A; 3 $\mathrm{mM})$ or compound $\mathrm{C}(50 \mu \mathrm{M})$ for $15 \mathrm{~min}$ prior to a 15-min incubation with A23 and/ or AICAR, and subsequent assessment of $\left[{ }^{3} \mathrm{H}\right]$ glucose and $\left[{ }^{14} \mathrm{C}\right]$ palmitate uptake $(A)$ and AMPK and ACC phosphorylation (B). Values are displayed as means $\pm \mathrm{SE}(n=$ 5). *Vs. control; $\wedge^{\wedge}$ vs. Oli; \$vs. AICAR; ${ }^{\wedge}$ vs. A23/AICAR $(P<0.05)$. of involvement of CaMKK $\beta$ in AMPK activation in cardiomyocytes points toward differences in the regulation of AMPK between heart and skeletal muscle.

With respect to the regulation of substrate uptake, we observed that in cardiomyocytes AMPK-activating stimuli (including contraction) enhance GLUT4 and CD36 translocation, as well as glucose and LCFA uptake, in agreement with our previous studies $(9,21)$. The inability of STO-609 or KN93 to inhibit AMPK-mediated substrate uptake matches the inability of both inhibitors to affect AMPK signaling and excludes the involvement of CaMKK $\beta$ or CaMKII herein. These findings are in line with our previous observations in cardiomyocytes from LKB1-knockout mice, in which AMPK-mediated increases in glucose and LCFA uptake were lost entirely (21), and therefore, they provide further evidence that LKB1, and not $\mathrm{CaMKK} \beta$, is the AMPK-activating kinase involved in the contraction-induced regulation of cardiac substrate uptake.

\section{Activation of $\mathrm{Ca}^{2+}$ Signaling Stimulates Translocation of} GLUT4 and CD36

Although the effect of $\left[\mathrm{Ca}^{2+}\right]_{\mathrm{i}}$-increasing stimuli on glucose transport in skeletal muscle has been a topic of several studies $(28,46,48)$, only few studies have shown GLUT4 translocation upon treatment with $\left[\mathrm{Ca}^{2+}\right]_{\mathrm{i}}$-increasing stimuli (e.g., see
Ref. 2). To our knowledge, no studies have shown that an elevation in $\left[\mathrm{Ca}^{2+}\right]_{\mathrm{i}}$ induces GLUT4 translocation in cardiomyocytes. The present study fills this gap, because cell surface biotinylation as well as subcellular fractionation reveal that both A23187 and thapsigargin induce GLUT4 translocation.

Reports on a relationship between $\mathrm{Ca}^{2+}$ signaling and CD36 translocation are limited to observations that caffeine induces CD36 translocation in skeletal muscle $(2,30)$, whereas no studies have been undertaken with respect to the heart. However, caffeine stimulates both $\mathrm{Ca}^{2+}$ signaling and AMPK signaling simultaneously, and therefore, this agent is not suited to study the effects of $\mathrm{Ca}^{2+}$ signaling separated from AMPK signaling. Each of the methods applied by us to assess CD36 translocation, including two-photon microscopy, clearly indicated enhanced CD36 translocation in response to A23187 or thapsigargin. The inability of these agents to activate AMPK indicates that $\mathrm{Ca}^{2+}$-induced CD36 translocation and also GLUT4 translocation occur independently from AMPK signaling. Furthermore, both $\mathrm{Ca}^{2+}$-induced GLUT4 translocation and CD36 translocation are sensitive to inhibition by STO-609 and KN93, pointing to the involvement of $\mathrm{CaMKK} \beta / \mathrm{CaMKs}$.

A positive control in our translocation studies was the translocation of both GLUT4 and CD36 in response to AMPK activation by oligomycin, in agreement with previous studies 
$(32,34)$. AMPK-mediated transporter translocation has been found to be dependent on phosphorylation-mediated inhibition of AS160 (18, 39), and in agreement, oligomycin treatment resulted in AS160 phosphorylation (Fig. 5A). Surprisingly, activation of $\mathrm{Ca}^{2+}$ signaling does not lead to phosphorylation of AS160, suggesting that AS160 does not regulate $\mathrm{Ca}^{2+}$ induced transporter translocation. Perhaps Rab GTPase-activating proteins other than AS160 (i.e., its homologue TBC1D1) are involved herein.

Besides the fact that the cell surface biotinylation experiments provide evidence for $\mathrm{Ca}^{2+}$-induced GLUT4 and CD36 translocation, these experiments also indicate that both transporters have properly arrived at the cell surface and have access to the extracellular milieu. This indicates that $\mathrm{Ca}^{2+}$ signaling is involved not only in the vesicle-mediated GLUT4 and CD36 translocation process but also in the subsequent fusion of the GLUT4- and CD36-containing vesicles with the plasma membrane.

\section{Activation of $\mathrm{Ca}^{2+}$ Signaling is Not Sufficient to Stimulate Glucose and LCFA Uptake}

In contrast to the parallel increases in AMPK-mediated substrate transporter translocation and AMPK-mediated substrate uptake, $\mathrm{Ca}^{2+}$-induced GLUT4 and CD36 translocation was not accompanied by increases in glucose and LCFA uptake. A likely explanation for these findings is that substrate transporter translocation (including subsequent fusion with the plasma membrane) is necessary but not sufficient for a given stimulus to increase substrate uptake. Hence, once they arrive at the cell surface, substrate transporters may need an additional activation step to become fully functional in substrate uptake. In the case of AMPK signaling, this signaling route might then be involved in both transporter translocation and cell surface activation of the transporters. In contrast, $\mathrm{Ca}^{2+}$ signaling appears to be involved only in the first step, the translocation, and ineffective in further cell surface activation. Evidence for such a two-step process in the stimulation of substrate transport has been reported previously in adipocytes as the inability of phosphatidylinositol-3,4,5-trisphosphate $\left(\mathrm{PIP}_{3}\right)$ to stimulate glucose uptake into these cells despite a successful translocation of GLUT4 to the plasma membrane (41). These latter findings indicate that $\mathrm{PIP}_{3}$ [the main product of insulin-stimulated phosphatidylinositol-3 kinase (PI3K) activation] is involved in insulin-stimulated GLUT4 translocation, but the GLUT4 activation step required for insulinstimulated glucose uptake is mediated by another, perhaps PI3K-independent, factor.

Similarly, in AMPK-mediated substrate uptake, the cell surface activation step would require different downstream mechanisms of AMPK compared with the translocation step. Specifically, whereas phosphorylation of AS160 (or TBC1D1) by AMPK is involved in the regulation of GLUT4 and CD36 translocation $(29,39)$, we do not necessarily expect AS160/ TBC1D1 to be involved in cell surface transporter activation at the cell surface since the Rab GTPase activity of both proteins is tightly connected to vesicular trafficking (13).

We can only speculate about the mechanism of AMPKmediated transporter activation at the cell surface. This activation step might involve a signaling-induced phosphorylation of each of the transporters individually. However, evidence for phosphorylation of GLUT4 or of CD36 to regulate transport activity is scarce. For CD36, merely ectophosphorylation was reported (19), whereas for GLUT4, a study in adipocytes showed that GLUT4 phosphorylation is inversely correlated with glucose uptake in response to insulin stimulation (5). Alternatively, both GLUT4 and CD36 might be activated in another combined event. For instance, GLUT4 and CD36 may translocate simultaneously to sarcolemmal regions that are nonfunctional in substrate uptake and then laterally migrate through the sarcolemma to a subdomain that is functional in
Fig. 7. Putative mechanism of the synergistic effect of $\mathrm{Ca}^{2+}$ and AMPK signaling on cardiac glucose and fatty acid uptake. Contraction as induced by an action potential (AP) leads to activation of AMPK. Both contraction-induced AMPK activation and a supraphysiological influx of $\mathrm{Ca}^{2+}$ into cardiomyocytes (e.g., induced by A23187) trigger translocation of GLUT4 and CD36 from separate AMPK-responsive and $\mathrm{Ca}^{2+}$ signaling-responsive endosomal subcompartments to the sarcolemma. AS160 is involved in AMPK-mediated GLUT4/CD36 translocation but not in $\mathrm{Ca}^{2+}$-induced transporter translocation. Both transporters arrive at the sarcolemma in an inactive state (depicted by a light gray fill color). Then, both transporters need an activation step [possibly lateral movement through the bilayer towards a specific membrane domain (depicted as a black membrane area) to become functional in substrate uptake (depicted by a dark gray fill color)]. This latter step is dependent on AMPK activation. Hence, whereas AMPKrecruited transporters do not require additional signaling pathways to effectuate translocation into enhanced substrate uptake, $\left[\mathrm{Ca}^{2+}\right]_{\mathrm{i}}$-recruited transporters depend on additional AMPK activation to become functional.

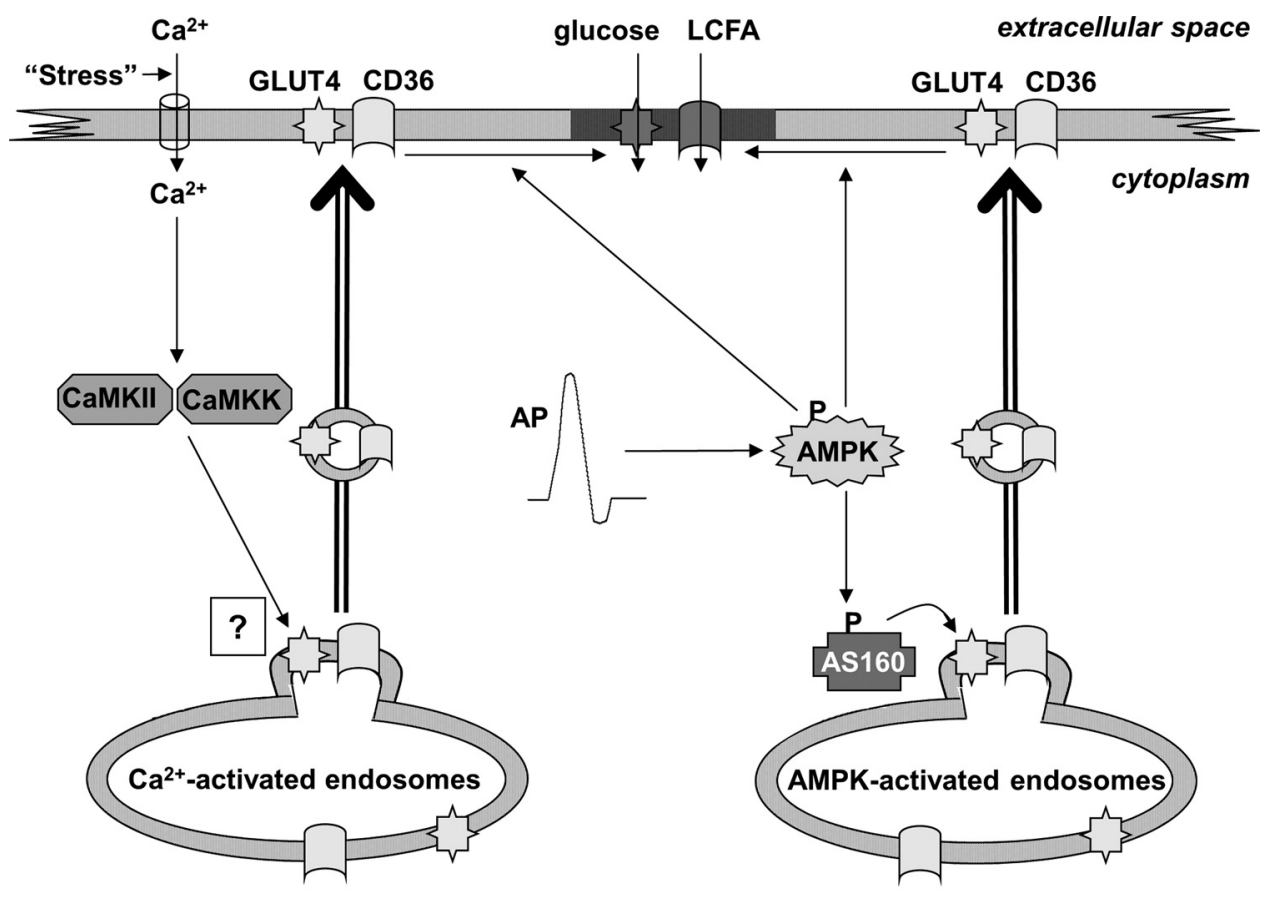

cardiomyocyte 
substrate uptake. Such sarcolemmal subdomains might include caveolae, which have been demonstrated to be necessary for LCFA uptake, at least in adipocytes (36). Furthermore, proteinprotein interactions could be involved in sarcolemmal activation of both transporters. In the case of GLUT4, reciprocal binding of GAPDH and hexokinase II has been shown to modulate GLUT4 activity (49).

\section{Combined Activation of $\mathrm{Ca}^{2+}$ Signaling and AMPK Signaling Synergistically Stimulates Glucose and LCFA Uptake in an AMPK-Sensitive Manner}

One major observation in this study is that activation of $\mathrm{Ca}^{2+}$ signaling, by itself unsuccessful in stimulating glucose and LCFA uptake into cardiomyocytes, substantially stimulated cardiac substrate uptake upon coactivation of AMPK signaling. Hence, $\mathrm{Ca}^{2+}$ signaling is dependent on separate coactivation of AMPK signaling to stimulate cardiac substrate uptake (illustrated in Fig. 7). In view of the ability of $\mathrm{Ca}^{2+}$ signaling to induce both GLUT4 and CD36 to translocate to the sarcolemma, once they have arrived at the cell surface, both transporters might undergo subsequent activation by AMPK signaling. The observation that pharmacological AMPK inhibitors entirely block substrate uptake induced by combined activation of $\mathrm{Ca}^{2+}$ and AMPK signaling provides support that activation of $\mathrm{Ca}^{2+}$-recruited transporters is indeed due to AMPK and not to an off-target effect of these stimuli.

The findings of this study point toward a gap in our knowledge of the role of $\mathrm{Ca}^{2+}$ and CaMKs on contraction stimulation of cardiac substrate uptake. Our findings revealed that upon an exaggerated rise in $\left[\mathrm{Ca}^{2+}\right]_{i}$ by pharmacological agents, activation of CaMKs will induce both GLUT4 and CD36 translocation. However, contraction stimulation did not activate $\mathrm{Ca}^{2+}$ signaling, at least not within the observation time (several minutes). Perhaps $\mathrm{Ca}^{2+}$-induced/CaMK-mediated transporter translocation might gain importance during pathological $\mathrm{Ca}^{2+}$ overload conditions (17), as mimicked by thapsigargin or A23187 treatment. Under such pathological conditions, AMPK activity would not be expected to be impaired and thus amply sufficient to mediate cell surface transporter activation. Then, $\mathrm{Ca}^{2+}$-induced transporter translocation can be effectuated into increased substrate uptake. Together, the present findings point toward the hypothetical presence of separate GLUT4/CD36containing subcompartments within the endosomes specifically responsive to a rise in $\left[\mathrm{Ca}^{2+}\right]_{i}$ next to the AMPK-responsive storage compartments for these transporters. The recruitment of transporters from these $\mathrm{Ca}^{2+}$-responsive storage compartments might be restricted to emergency situations (like hypoxia and fight/flight response) to meet the excessive metabolic demands of the heart in such conditions.

Yet the basal activity of CaMKs in the heart or the changes in activation of CaMKs on a millisecond time scale are not yet known. Similarly to $\mathrm{Ca}^{2+}$ waves that activate CaMK signaling, AMPK activation status might also fluctuate on the millisecond time scale. Expectedly, there would be some delay to the CaMK signaling, because the increased energy demand (that is sensed by AMPK through changes in adenine nucleotide levels) evolves from the $\mathrm{Ca}^{2+}$-induced cardiomyocyte contraction. Thus, we could speculate about $\mathrm{Ca}^{2+} / \mathrm{CaMK}$ signaling preparing the cardiomyocyte for substrate uptake during contraction by inducing transporter translocation, which in the case of actual energy requirement is finalized by AMPK into substrate uptake to refill cellular energy. At present, it is not possible for us to determine CaMK and AMPK signaling changes occurring at such a rapid pace. In conclusion, we cannot exclude a possible millisecond action of CaMKs on transporter translocation under normal physiological conditions.

Finally, identification of the proteins functioning downstream of CaMKs in $\mathrm{Ca}^{2+}$-induced translocation of GLUT4 and CD36 might provide novel targets to influence cardiac substrate uptake.

\section{GRANTS}

This work was performed in part within the framework of the Center for Translational Molecular Medicine, project PREDICCt (Grant no. 01C-104), and supported by the Netherlands Heart Foundation, Dutch Diabetes Research Foundation, and Dutch Kidney Foundation. D. Neumann is the recipient of a VIDI-Innovational Research Grant from the Netherlands Organization of Scientific Research (NWO-ALW Grant no. 864.10.007).

\section{DISCLOSURES}

No conflicts of interest, financial or otherwise, are declared by the authors.

\section{AUTHOR CONTRIBUTIONS}

Y.A., R.N.-U., N.H., M.J.K., W.A.C., and J.J.L. performed experiments; Y.A., R.W.S., R.N.-U., J.W.H., M.J.K., M.A.J.v.Z., and J.J.L. analyzed data; Y.A., R.W.S., J.W.H., D.N., and J.J.L. interpreted results of experiments; Y.A. and J.J.L. prepared figures; Y.A. and J.J.L. drafted manuscript; Y.A., R.W.S., R.N.-U., N.H., J.W.H., M.J.K., W.A.C., M.A.J.v.Z., A.B., D.N., J.F.G., and J.J.L. approved final version of manuscript; J.W.H., A.B., D.N., J.F.G., and J.J.L. edited and revised manuscript; J.J.L. conception and design of research.

\section{REFERENCES}

1. Abbott MJ, Bogachus LD, Turcotte LP. AMPK $\alpha_{2}$ deficiency uncovers time dependency in the regulation of contraction-induced palmitate and glucose uptake in mouse muscle. J Appl Physiol 111: 125-134, 2011.

2. Abbott MJ, Edelman AM, Turcotte LP. CaMKK is an upstream signal of AMP-activated protein kinase in regulation of substrate metabolism in contracting skeletal muscle. Am J Physiol Regul Integr Comp Physiol 297: R1724-R1732, 2009.

3. Anderson ME. Calmodulin kinase signaling in heart: an intriguing candidate target for therapy of myocardial dysfunction and arrhythmias. Pharmacol Ther 106: 39-55, 2005.

4. Auger JM, Kuijpers MJ, Senis YA, Watson SP, Heemskerk JW. Adhesion of human and mouse platelets to collagen under shear: a unifying model. FASEB J 19: 825-827, 2005.

5. Begum N, Draznin B. Effect of streptozotocin-induced diabetes on GLUT-4 phosphorylation in rat adipocytes. J Clin Invest 90: 1254-1262, 1992.

6. Bers DM, Guo T. Calcium signaling in cardiac ventricular myocytes. Ann NY Acad Sci 1047: 86-98, 2005.

7. Chabowski A, Coort SL, Calles-Escandon J, Tandon NN, Glatz JF, Luiken JJ, Bonen A. The subcellular compartmentation of fatty acid transporters is regulated differently by insulin and by AICAR. FEBS Lett 579: 2428-2432, 2005.

8. Chiba H, Schneider NS, Matsuoka S, Noma A. A simulation study on the activation of cardiac CaMKII delta-isoform and its regulation by phosphatases. Biophys J 95: 2139-2149, 2008.

9. Coort SL, Hasselbaink DM, Koonen DP, Willems J, Coumans WA, Chabowski A, van der Vusse GJ, Bonen A, Glatz JF, Luiken JJ. Enhanced sarcolemmal FAT/CD36 content and triacylglycerol storage in cardiac myocytes from obese zucker rats. Diabetes 53: 1655-1663, 2004.

10. Dirkx E, Schwenk RW, Coumans WA, Hoebers N, Angin Y, Viollet B, Bonen A, van Eys GJ, Glatz JF, Luiken JJ. Protein kinase D1 is essential for contraction-induced glucose uptake but is not involved in fatty acid uptake into cardiomyocytes. J Biol Chem 287: 5871-5881, 2012.

11. Dransfeld O, Rakatzi I, Sasson S, Eckel J. Eicosanoids and the regulation of cardiac glucose transport. Ann NY Acad Sci 967: 208-216, 2002. 
12. Fischer Y, Rose H, Kammermeier H. Highly insulin-responsive isolated rat heart muscle cells yielded by a modified isolation method. Life Sci 49: 1679-1688, 1991.

13. Fukuda M. TBC proteins: GAPs for mammalian small GTPase Rab? Biosci Rep 31: 159-168, 2011.

14. Glatz JF, Luiken JJ, Bonen A. Membrane fatty acid transporters as regulators of lipid metabolism: implications for metabolic disease. Physiol Rev 90: 367-417, 2010.

15. Gowans GJ, Hawley SA, Ross FA, Hardie DG. AMP is a true physiological regulator of AMP-activated protein kinase by both allosteric activation and enhancing net phosphorylation. Cell Metab 18: 556-566, 2013.

16. Green MF, Scott JW, Steel R, Oakhill JS, Kemp BE, Means AR. $\mathrm{Ca} 2+/$ Calmodulin-dependent protein kinase kinase beta is regulated by multisite phosphorylation. J Biol Chem 286: 28066-28079, 2011.

17. Gusarova GA, Trejo HE, Dada LA, Briva A, Welch LC, Hamanaka RB, Mutlu GM, Chandel NS, Prakriya M, Sznajder JI. Hypoxia leads to $\mathrm{Na}, \mathrm{K}-\mathrm{ATPase}$ downregulation via $\mathrm{Ca}(2+)$ release-activated $\mathrm{Ca}(2+)$ channels and AMPK activation. Mol Cell Biol 31: 3546-3556, 2011.

18. Geraghty KM, Chen S, Harthill JE, Ibrahim AF, Toth R, Morrice NA, Vandermoere F, Moorhead GB, Hardie DG, MacKintosh C. Regulation of multisite phosphorylation and 14-3-3 binding of AS160 in response to IGF-1, EGF, PMA and AICAR. Biochem J 407: 231-241, 2007.

19. Guthmann F, Maehl P, Preiss J, Kolleck I, Rustow B. Ectoprotein kinase-mediated phosphorylation of FAT/CD36 regulates palmitate uptake by human platelets. Cell Mol Life Sci 59: 1999-2003, 2002.

20. Habets DD, Coumans WA, Voshol PJ, den Boer MA, Febbraio M, Bonen A, Glatz JF, Luiken JJ. AMPK-mediated increase in myocardial long-chain fatty acid uptake critically depends on sarcolemmal CD36. Biochem Biophys Res Commun 355: 204-210, 2007.

21. Habets DD, Coumans WA, El Hasnaoui M, Zarrinpashneh E, Bertrand L, Viollet B, Kiens B, Jensen TE, Richter EA, Bonen A, Glatz JF, Luiken JJ. Crucial role for LKB1 to AMPKalpha2 axis in the regulation of $\mathrm{CD} 36$-mediated long-chain fatty acid uptake into cardiomyocytes. Biochim Biophys Acta 1791: 212-219, 2009.

22. Habets DD, Thurmond DC, Coumans WA, Bonen A, Glatz JF, Luiken JJ. Munc18c is not rate-limiting for glucose and long-chain fatty acid uptake in the heart. Mol Cell Biochem 322: 81-86, 2009.

23. Hagen BM, Boyman L, Kao JP, Lederer WJ. A comparative assessment of fluo $\mathrm{Ca} 2+$ indicators in rat ventricular myocytes. Cell Calcium 52: $170-181,2012$.

24. Hatori N, Fine BP, Nakamura A, Cragoe E Jr, Aviv A. Angiotensin II effect on cytosolic $\mathrm{pH}$ in cultured rat vascular smooth muscle cells. J Biol Chem 262: 5073-5078, 1987.

25. Hawley SA, Pan DA, Mustard KJ, Ross L, Bain J, Edelman AM, Frenguelli BG, Hardie DG. Calmodulin-dependent protein kinase kinase-beta is an alternative upstream kinase for AMP-activated protein kinase. Cell Metab 2: 9-19, 2005.

26. Heemskerk JW, Willems GM, Rook MB, Sage SO. Ragged spiking of free calcium in ADP-stimulated human platelets: regulation of puff-like calcium signals in vitro and ex vivo. J Physiol 535: 625-635, 2001.

27. Hopkins TA, Dyck JR, Lopaschuk GD. AMP-activated protein kinase regulation of fatty acid oxidation in the ischaemic heart. Biochem Soc Trans 31: 207-212, 2003.

28. Jensen TE, Rose AJ, Jørgensen SB, Brandt N, Schjerling P, Wojtaszewski JF, Richter EA. Possible CaMKK-dependent regulation of AMPK phosphorylation and glucose uptake at the onset of mild tetanic skeletal muscle contraction. Am J Physiol Endocrinol Metab 292: E1308-E1317, 2007

29. Jessen N, An D, Lihn AS, Nygren J, Hirshman MF, Thorell A, Goodyear LJ. Exercise increases TBC1D1 phosphorylation in human skeletal muscle. Am J Physiol Endocrinol Metab 301: E164-E171, 2011.

30. Lally JS, Jain SS, Han XX, Snook LA, Glatz JF, Luiken JJ, McFarlan J, Holloway GP, Bonen A. Caffeine-stimulated fatty acid oxidation is blunted in CD36 null mice. Acta Physiol (Oxf) 205: 71-81, 2012.

31. Luiken JJ, Coort SL, Koonen DP, van der Horst DJ, Bonen A, Zorzano A, Glatz JF. Regulation of cardiac long-chain fatty acid and glucose uptake by translocation of substrate transporters. Pflugers Arch 448: $1-15,2004$

32. Luiken JJ, Coort SL, Willems J, Coumans WA, Bonen A, van der Vusse GJ, Glatz JF. Contraction-induced fatty acid translocase/CD36 translocation in rat cardiac myocytes is mediated through AMP-activated protein kinase signaling. Diabetes 52: 1627-1634, 2003.
33. Luiken JJ, van Nieuwenhoven FA, America G, van der Vusse GJ, Glatz JF. Uptake and metabolism of palmitate by isolated cardiac myocytes from adult rats: involvement of sarcolemmal proteins. J Lipid Res 38: 745-758, 1997.

34. Luiken JJ, Vertommen D, Coort SL, Habets DD, El Hasnaoui M, Pelsers MM, Viollet B, Bonen A, Hue L, Rider MH, Glatz JF. Identification of protein kinase $\mathrm{D}$ as a novel contraction-activated kinase linked to GLUT4-mediated glucose uptake, independent of AMPK. Cell Signal 20: 543-556, 2008.

35. Nozaki S, Tanaka T, Yamashita S, Sohmiya K, Yoshizumi T, Okamoto F, Kitaura Y, Kotake C, Nishida H, Nakata A, Nakagawa T, Matsumoto K, Kameda-Takemura K, Tadokoro S, Kurata Y, Tomiyama Y, Kawamura K, Matsuzawa Y. CD36 mediates long-chain fatty acid transport in human myocardium: complete myocardial accumulation defect of radiolabeled long-chain fatty acid analog in subjects with CD36 deficiency. Mol Cell Biochem 192: 129-135, 1999.

36. Pohl J, Ring A, Korkmaz U, Ehehalt R, Stremmel W. FAT/CD36mediated long-chain fatty acid uptake in adipocytes requires plasma membrane rafts. Mol Biol Cell 16: 24-31, 2005.

37. Rose AJ, Hargreaves M. Exercise increases Ca2+-calmodulin-dependent protein kinase II activity in human skeletal muscle. J Physiol 553: 303-309, 2003.

38. Rose AJ, Kiens B, Richter EA. Ca2+-calmodulin-dependent protein kinase expression and signalling in skeletal muscle during exercise. $J$ Physiol 574: 889-903, 2006.

39. Samovski D, Su X, Xu Y, Abumrad NA, Stahl PD. Insulin and AMPK regulate FA translocase/CD36 plasma membrane recruitment in cardiomyocytes via Rab GAP AS160 and Rab8a Rab GTPase. J Lipid Res 53: 709-717, 2012.

40. Schwenk RW, Dirkx E, Coumans WA, Bonen A, Klip A, Glatz JF, Luiken JJ. Requirement for distinct vesicle-associated membrane proteins in insulin- and AMP-activated protein kinase (AMPK)-induced translocation of GLUT4 and CD36 in cultured cardiomyocytes. Diabetologia 53: 2209-2219, 2010.

41. Sweeney G, Garg RR, Ceddia RB, Li D, Ishiki M, Somwar R, Foster LJ, Neilsen PO, Prestwich GD, Rudich A, Klip A. Intracellular delivery of phosphatidylinositol $(3,4,5)$-trisphosphate causes incorporation of glucose transporter 4 into the plasma membrane of muscle and fat cells without increasing glucose uptake. J Biol Chem 279: 32233-32242, 2004.

42. Teixeira SS, Tamrakar AK, Goulart-Silva F, Serrano-Nascimento C, Klip A, Nunes MT. Triiodothyronine acutely stimulates glucose transport into L6 muscle cells without increasing surface GLUT4, GLUT1, or GLUT3. Thyroid 22: 747-754, 2012.

43. van Oort MM, van Doorn JM, Bonen A, Glatz JF, van der Horst DJ, Rodenburg KW, Luiken JJ. Insulin-induced translocation of CD36 to the plasma membrane is reversible and shows similarity to that of GLUT4. Biochim Biophys Acta 1781: 61-71, 2008.

44. Wang YG, Dedkova EN, Ji X, Blatter LA, Lipsius SL. Phenylephrine acts via IP3-dependent intracellular NO release to stimulate L-type Ca2+ current in cat atrial myocytes. $J$ Physiol 567: 143-157, 2005.

45. Wang YX, Kotlikoff M. Muscarinic signaling pathway for calcium release and calcium-activated chloride current in smooth muscle. Am J Physiol Cell Physiol 273: C509-C519, 1997.

46. Witczak CA, Jessen N, Warro DM, Toyoda T, Fujii N, Anderson ME, Hirshman MF, Goodyear LJ. CaMKII regulates contraction- but not insulin-induced glucose uptake in mouse skeletal muscle. Am J Physiol Endocrinol Metab 298: E1150-E1160, 2010.

47. Woods A, Dickerson K, Heath R, Hong SP, Momcilovic M, Johnstone SR, Carlson M, Carling D. Ca2+/calmodulin-dependent protein kinase kinase-beta acts upstream of AMP-activated protein kinase in mammalian cells. Cell Metab 2: 21-33, 2005.

48. Wright DC, Hucker KA, Holloszy JO, Han DH. Ca2 + and AMPK both mediate stimulation of glucose transport by muscle contractions. Diabetes 53: 330-335, 2004.

49. Zaid H, Talior-Volodarsky I, Antonescu C, Liu Z, Klip A. GAPDH binds GLUT4 reciprocally to hexokinase-II and regulates glucose transport activity. Biochem J 419: 475-484, 2009.

50. Zorzano A, Sevilla L, Camps M, Becker C, Meyer J, Kammermeier H, Muñoz P, Gumà A, Testar X, Palacín M, Blasi J, Fischer Y. Regulation of glucose transport, and glucose transporters expression and trafficking in the heart: studies in cardiac myocytes. Am J Cardiol 80: 65A-76A, 1997. 